\title{
Societal lssues in Materials Science and Technology
}

\section{Morris Cohen}

The following is an edited transcription of the David Turnbull Lecture given by Morris Cohen at the 1994 MRS Spring Meeting. Cohen is Institute Professor Emeritus, Department of Materials Science and Engineering, at the Massachusetts Institute of Technology.

I am extremely grateful for this occasion to honor Professor David Turnbull, whom I admire very much and who has contributed so elegantly to advance materials science. His many achievements have been acclaimed by the most eminent scholarly awards. David Turnbull was among the first to appreciate and teach the multidisciplinarity of materials science. In fact, he has termed it a superdiscipline covering "the characterization, understanding, and control of the structure of matter at the ultramolecular level and the relating of this structure to properties." 1 My lecture builds on this concept of materials science but broadens this branch of knowledge and actioity to include materials engineering, thereby connecting with the technologies through which materials help serve societal needs and national goals.

I am going to use this special opportunity to reflect in a rather general way on the field of materials science-its place in the scheme of things, its changing nature, and its novel role in national and societal issues. All this is embedded in the ongoing debate on the interdependence between science and technology and their relationship to national well-being, often translated to mean industrial and economic performance, quality of life and health care, environmental protection, and national security

Clearly, the materials community must have some part to play in various aspects of the country's prosperity and standard of living, and that raises serious questions as to what a technical association such as the Materials Research Society might choose to do about it, if anything. These complex matters are particularly critical at the present time when science and technology are coming under increasing public and governmental scrutiny-even pressure-to better serve the needs and the values of the nation.

\section{Materials as a Basic Resource of Society}

One might first ask why materials are important enough to demand attention in this societal context. To start with, materials rank among the most basic resources of society, even of civilizations through the ages (see Table I).

\section{Table I: Some Basic Resources} of Humankind.

Air, water, and food
Living space
Materials
Energy
Manpower
Knowledge

Materials have been an intimate factor in human existence ever since the beginning of recorded history. In fact, materials are so ubiquitous that the public is only vaguely aware of their nature and hardly realizes that materials constitute a special kind of physical matter, namely, the substances which can be employed for making things. This is an apt notion of what materials are because it leads directly to a

Material Matters is a forum for expressing personal points of view on issues of interest to the materials community. definition of the frequently used-perhaps even overused-term, "technology."

Simply stated, technology is the systematic knowledge, or the technical advance, of the means for making things-which on sufficient scale denotes manufacturing. Whereas the output of science can be regarded as knowledge, the output of technology is goods and services. The word "technology" is also often extended to include the products being manufactured as well as the processes or concepts being invoked. Technological development is important because it expands society's ability to generate and apply knowledge. Notwithstanding the diversity of approaches and methods that may be employed, it is almost always materials that are being purposefully formed or assembled in the technology.

High-technology products are those whose operation or function is relatively intricate. Typical examples are communications and electronic equipment, computers and robotics, aircraft and spacecraft, military armament and rocketry, fiber optics, professional and scientific instruments, and engines of many sorts. The materials that enable these high-technology products to function successfully are often referred to as advanced materials. They are usually state-of-the-art developments or traditional materials that have been recently improved. They are generally high-performance, comparatively highcost materials, representative of the latest in production or end-use products.

\section{The Global Materials Cycle}

Well before materials appear in end products to serve societal objectives, their ingredients participate to various degrees in what has come to be viewed as a global materials cycle 2 (Figure 1 ). This cradle-tograve circuit extracts raw materials from nature, largely by mining, drilling, or harvesting; converts the raw materials into bulk materials, such as cements, metals, chemicals, rubber, silicon, petroleum, lumber, and fibers; and refines the bulk materials into engineering materials, such as ceramics and glass, alloys, semiconductors, optical fibers, plastics and elastomers, and composites. Then the engineering materials are further treated and shaped as needed to be assembled into innumerable kinds of products for society, including machines, devices, appliances, construction and infrastructure, munitions, and all forms of transport. After these products have ended their useful purposes, they are typically discarded, and their constituents are recycled to function again if economically feasible, or they are disposed of back to the earth from 


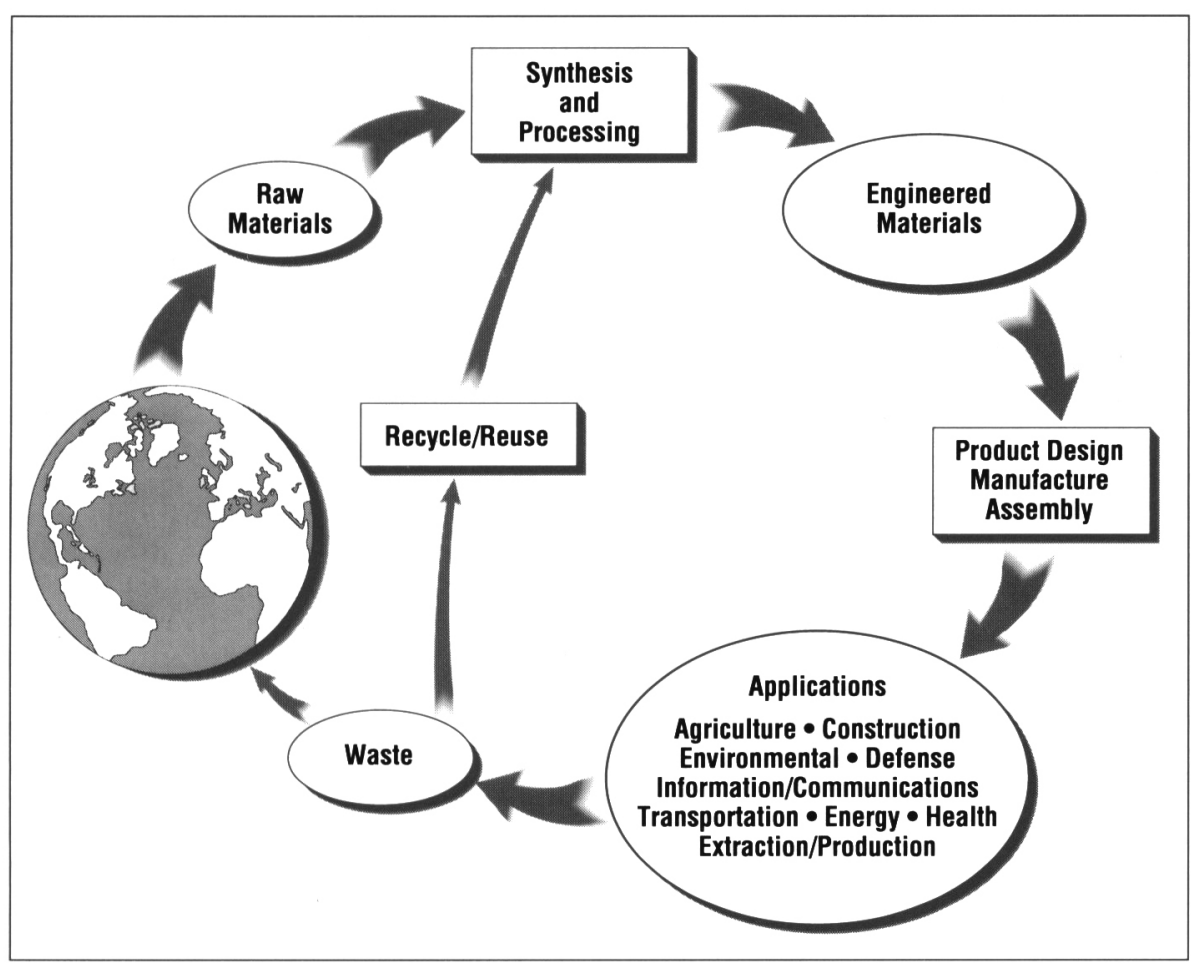

Figure 1. Schematic representation of the global materials cycle. ${ }^{3}$

whence they came, thus completing their complex journey through the global materials cycle.

Some 15 billion tons of raw materials are taken from nature annually on this planet, and in passing around the global circuit, they link companies and countries together through national and international commerce and competition. Value is added to the materials at each step of the way by inputs of labor, energy, and capital, and in a market-oriented system, these economic factors enter into the "driving force" which keeps the materials moving from stage-to-stage throughout their respective lifetimes. Overall, it is the societal demand, reflected by what people and institutions are willing to pay for, that provides a pull on the materials flow along their global routes.

One should note in this connection that there are many interactions between materials, energy, and the environment. About one-half of the energy consumed by manufacturing industries in the United States goes into the cost of materials produced and fabricated. Conversely, materials are indispensable for generating and transmitting energy in the first place. Indeed, virtually all the modern energyconversion technologies are presently materials-limited with regard to efficien- cy, reliability, safety, or cost-effectiveness. At the same time, it is obvious just from the workings of the materials cycle that the processing, use, and disposal of materials require special attention to minimize the attendant environmental problems, all of which can add significantly to the total cost of industrial production and can also seriously degrade the quality of life.

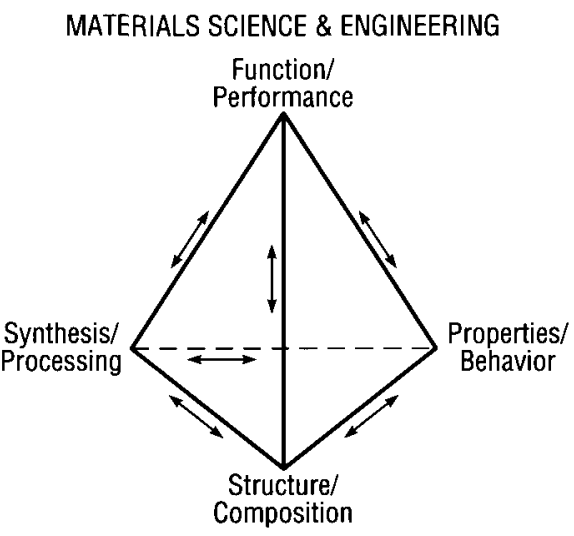

Figure 2. Model of the multidiscipline of materials science and engineering illustrating its four main elements and their mutual interactions. ${ }^{4}$

\section{Materials Science and Engineering}

A good insight to the nature of materials per se may be gained through the multidiscipline of materials science and engineering (MSE). MSE is concerned with the generation and application of knowledge related to the synthesis and processing of materials, their composition and structure, their properties and behavior, and their function and performance in machines, structures, devices, and end products (Figure 2). The doubleheaded arrows connecting the vertices of the tetrahedron are meant to show that each of the elements of MSE interacts reciprocally with, and gives valuable information about, the others, all contributing to a growing system of fundamental knowledge and practical application of materials. The scope of MSE ranges from the most basic understanding of condensed matter to useful functions for human needs. MSE does not replace any of the existing disciplines, but provides an interconnected medium of knowledge and endeavor in which any relevant branch of learning can contribute to the understanding of materials or help make them available and serviceable. When visualized this way, MSE operates as a multidiscipline; it acts as a multidimensional knowledge-transfer system that offers valuable interactions among otherwise separate disciplines.

MSE is also a continuous medium for the back-and-forth intermixing of scientific and empirical knowledge: i.e., scientific information arising from materials $R \& D$ and empirical information reflecting the needs and experience of society. This situation means that there are no rational barriers between science and engineering in the field of materials. Materials research, even though sometimes classed as "basic," is appropriately exposed to societal requirements for potential utility and so, strictly speaking, can be "purposeful" or "applied" or "strategic" from the standpoint of MSE.

Materials comprise key components of almost every kind of technology, but simultaneously, materials also form an integral part of the natural world. In a real sense, then, MSE puts society into a partnership with nature when society seeks to advance technologies to achieve national goals, such as economic growth, industrial productivity, national security, and quality of life.

Because of the indispensable and enabling functions of materials in diverse technologies, MSE is intimately linked to, and benefited by, many scientific and engineering disciplines. Accordingly, the professionals associated with MSE are quite diversified, as reflected, for example, by 
the membership of the Materials Research Society. In technical outlook and priorities, MRS members are probably representative of a cohort in the United States of approximately 1.5 million scientists, engineers, and technologists, who spend an appreciable fraction of their efforts on some aspect of MSE. But as it happens, a substantial fraction of that population would identify themselves primarily with their specific degrees or disciplines in science or engineering rather than as materials scientists or engineers. This means that the professionals who study and work with materials are not staunchly coupled through a specific branch of learning, but rather come together through various interests that somehow interconnect through the multidiscipline of MSE and its related technologies.

\section{Materials science and engineering is a purposeful enterprise closely coupled to mankind's requirements for products, structures, machines, and devices.}

Thus, the unity and coherence which arise in MSE are largely self-organizing, but in disparate ways, and it is difficult to find a single agency or institution that can truly represent the field of MSE or speak with an authoritative voice concerning its importance, its trends, and its support. There is strength in the fact that materials are so pervasive in character and in utility, but a persistent problem exists in that the role of materials in technologies generally is so diversified. This is a dilemma that materials-oriented societies will have to confront as they look to the future.

\section{Basic Versus Strategic Research}

It is well to inquire at this point how the field of materials is regarded, or evaluated, by the federal government. MSE need not be overly concerned by the current debate about basic versus applied or strategic research. Purely basic research, by definition, is performed without thought of practical results; it creates fundamental knowledge and understanding of nature and its laws, but it is not designed to have value for useful technologies. Yet such basic science is reasonably well-funded by government. It turns out that the thoughtful public has an inherent, even if detached, curiosity about the structure of the universe and the way the nat- ural world functions. Indirectly, this interest extends to such profound questions as the origin and expansion of the universe, the beginning and evolution of life, elementary-particle physics and the ultimate state of matter, the detection of dark matter in the cosmos, and the advance of pure mathematics signifying new capabilities of the human mind.

As we have now learned, however, from the cancellation of the Superconducting Super Collider-intended to reach a great step closer to the ultimate nature of matter-there are cost limits, depending on social and economic conditions at the time, beyond which society (as reflected by Congress) is not prepared to go. This does not necessarily mean any lessening of high regard for very basic science; it primarily manifests the escalation of other critical human needs arising from changing social conditions.

Most other so-called basic research, especially in materials, is at least remotely mission-oriented; i.e., it is performed with some general or long-range utilitarian objective. As a result, this kind of basic research becomes more related to applied or strategic research than to the purely basic research previously mentioned.

\section{Federal R\&D Initiatives in \\ Civilian Technologies}

The federal government is projected to spend about $4 \%$ more overall for R\&D in FY95 than in FY94 ( $\$ 71$ billion versus $\$ 68$ billion, not including facilities) and $6 \%$ more for the National Science Foundation in FY95 than in FY94 ( $\$ 3.2$ billion versus $\$ 3.0$ billion). These increases are not insignificant considering the constraints on total discretionary federal spending. At the same time, there will be increasing emphasis on civilian technology R\&D. President Clinton's Progress Report of November $1993^{5}$ stresses that "Technology is the engine of economic growth, creating new jobs, building new industries, and improving our standard of living. Technology is also a powerful tool for making government more efficient and responsive, harmonizing our economic growth and environmental objectives, and making more efficient use of our energy resources. Increasingly, leadership in the use and commercialization of technology provides the foundation for America's status as an economic and military superpower." This affirmation of technology in contributing to the nation's future might be regarded as the "Clinton-Gore doctrine" from the standpoint of R\&D.

It is obvious from the initiatives and technologies cited in the President's report that there will be a strong governmental thrust toward the civilian sector of the economy, with national objectives tied to societal and industrial enhancement. Mentioned among many other initiatives are the Technology Reinvestment Program to promote the transition from defense to civilian industrial capabilities; the Advanced Technology Program to stimulate the development of high-risk commercial technologies, being organized by the National Institute of Standards and Technology in the Department of Commerce; Dual-Use Technologies for Military and Commercial Products and Processes, being administered by the Advanced Research Projects Agency in the Department of Defense; the Clean-Car Initiative for developing technologies leading to a new generation of fuel-efficient, nonpolluting vehicles in collaboration with the U.S. automobile industry; the National Information Infrastructure to foster a huge web of advanced communication networks; and a system of manufacturing extension centers to assist in the modernization of small- and mediumsized businesses.

Concerning basic science, the President's report notes "the inseparable links between fundamental scientific research and technological progress," quoting a theme of the groundbreaking Vannevar Bush report on Science-The Endless Frontier, which declares that "scientific advances are the wellspring of technical innovations whose benefits are seen in economic growth, improved health care, and many other areas." 6 However, the basic science being mainly referred to in this context is not the purely basic type mentioned previously, but the more oriented version that can connect, even if in the distant future, to applied or strategic $R \& D$ in line with the special accent being placed on technological strategies.

\section{Federal Status of Materials R\&D}

We now come back to the question: Where does the area of materials stand in the light of the foregoing national initiatives? It is important to assess the prevailing changes in the national mood. Intrinsically, the very nature of MSE-with its focus on materials via a seamless spectrum of science and engineering-is entirely consistent with the present emphasis on advanced technologies by the federal government. This fact is demonstrated by the Advanced Materials and Processing Program (AMPP), which is a part of the President's FY94 budget. According to Dr. John H. Gibbons, director of the Office of Science and Technology Policy, who wrote the letter of transmittal to Congress, "The economic pros- 


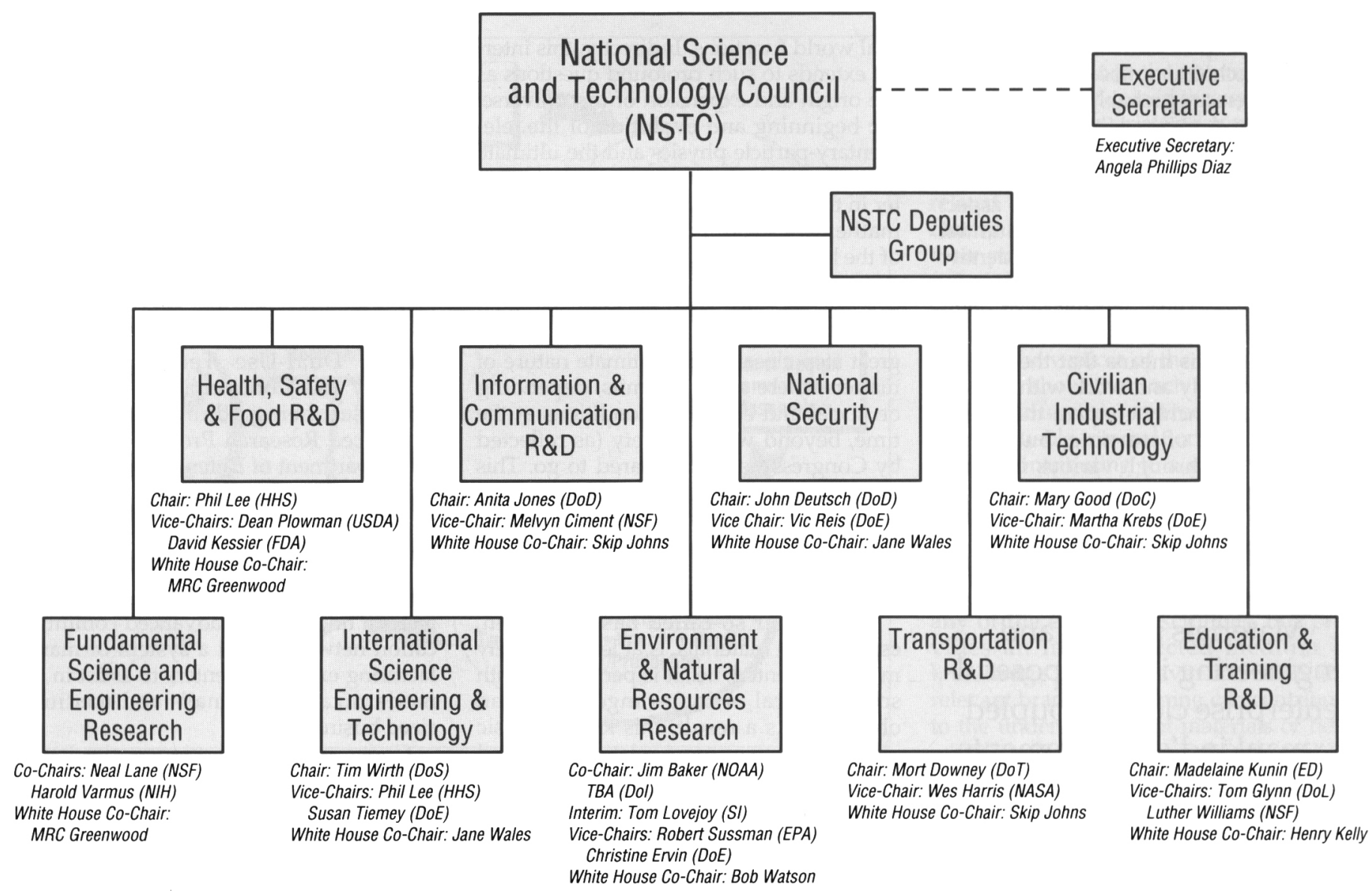

Figure 3. The National Science and Technology Council and its committees. Organizational chart taken from the 1994 National Academy of Engineering Regional Meetings.

perity, environmental well-being, and quality of life of all Americans are linked to the development of advanced materials and processing technologies. Improved materials and processes can contribute to a number of national priorities: energy efficiency, environmental quality, national security, health care, information and communication, infrastructure, transportation."7

However, several downsides should be noted for materials. The total FY94 R\&D budget for AMPP, summed up over the 10 listed federal agencies, is actually $5 \%$ less than for FY93. Moreover, whereas the FY93 AMPP was established as a Presidential Initiative, the FY94 AMPP was submitted at the lower level of the Federal Coordinating Council for Science, Engineering, and Technology (FCCSET). Perhaps even more significantly, FCCSET has now been dissolved because, according to Vice President Gore, "it lacks the teeth to set priorities, direct policy, and participate fully in the budget process. It can't compel agencies to participate in its

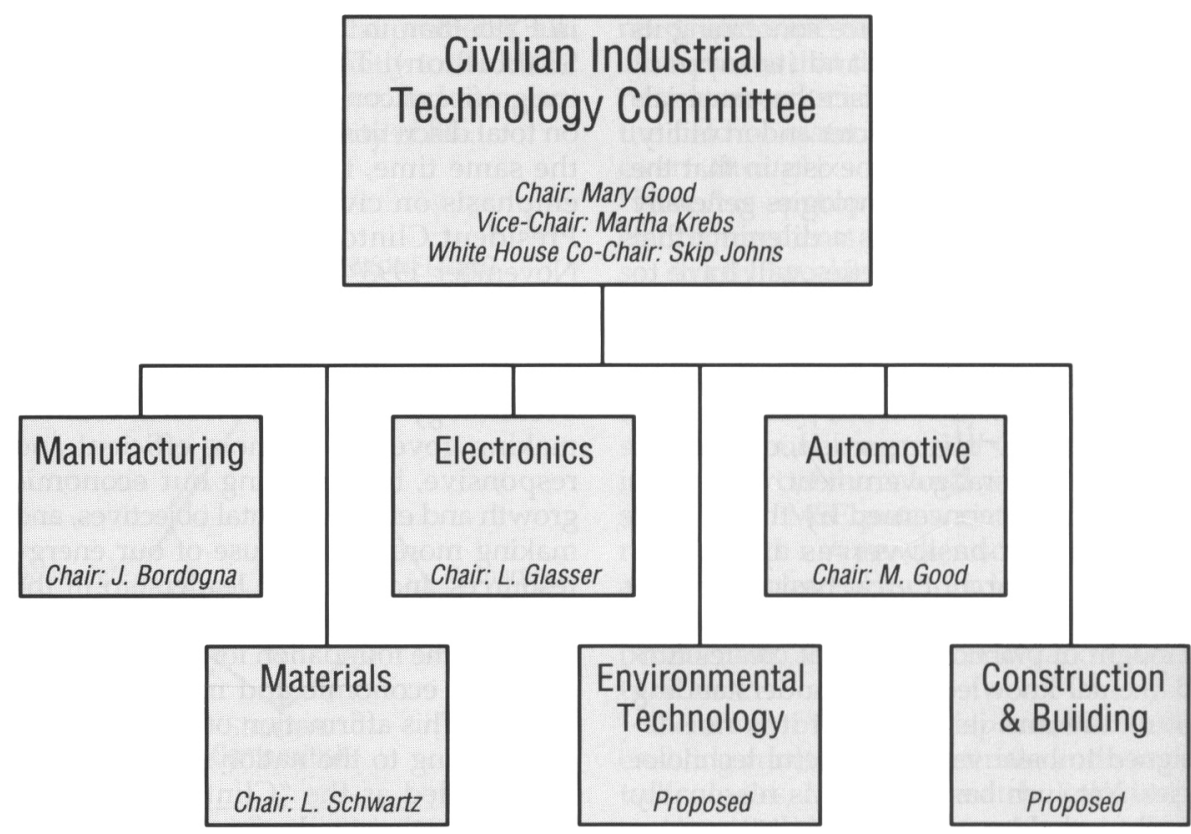

Figure 4. Civilian Industrial Technology Committee and its subcommittees. Organizational chart taken from the 1994 National Academy of Engineering Regional Meetings. 
projects, nor can it tell agencies how to spend funds." 8 In addition, other materials-related governmental committees, deemed not to be sufficiently effective, have been discontinued, including the National Critical Materials Council, the Materials Caucus, and the Congressional Materials Subcommittee.

High-level coordination for federally sponsored R\&D will now be vested in a newly created National Science and Technology Council (NSTC), to be chaired by President Clinton himself, thus upgrading science and technology to the status of other Presidentially headed toplevel councils, namely the National Security Council, the National Economic Council, and the Domestic Policy Council. NSTC is to have nine R\&D coordinating committees, as illustrated in Figure 3. Evidently, the entire sweep of federally supported R\&D will be planned and coordinated by the NSTC; the committees comprising NSTC have been accordingly designated to identify with national goals. MSE may play active roles in many of these important domains, particularly in Fundamental Science and Engineering Research. So far, however, materials per se are only highlighted in a subcommittee of the Civilian Industrial Technology Committee (Figure 4); but materials R\&D will surely be involved as enabling technologies in the planning of the other subcommittees portrayed in Figure 4.

It should be mentioned that the NSTC structure is still new and not yet fully organized or in effective operation. As far as materials are concerned, much will depend on the initiative and responsiveness of the MSE community in the unfolding process.

\section{Materials R\&D and National Goals Through Technologies}

Obviously, with this type of organizational structure, the role of materials will often come in as enabling technologies, i.e., to function appropriately in manufacturing and in end products, rather than as a high-priority endeavor in itself for the development of new materials and new structure-property relationships. Such materials R\&D is still essential, but it will be favored if it has a chance to implement a technology for some societal purpose. It is still feasible, even desirable, for individual ideas and investigator-initiated research to contribute in constructive ways to these long-term programs, particularly as part of a cooperative effort.

So, the materials profession is facing a new challenge. Going beyond continuing progress toward understanding the complex relationships which interconnect the synthesis and processing of materials, their composition and structure, their properties and behavior, and their function and performance, the community is now being urged by the federal government to focus more attention on the enabling function and performance of materials in technologies that will contribute to national productivity and economic growth (Figure 5). This means that in undertaking materials $R \& D$, investigators would do well to think about national goals and potential benefits to society. It appears that MSE may not prosper unto itself hereafter as a critical multidiscipline unless its role is linked more supportively to technologies that will help fill the needs of society sooner or later. All these matters will surely encourage more $R \& D$ collaboration between universities and industry. And sooner or later, cost factors will have to be taken into account-economic costs bearing on eventual commercialization and social costs bearing on the quality of the environment. Technical societies related to materials and materials departments in academia will have to consider these issues.

In looking ahead, it is well to keep in mind that, in general, technologies advance successfully most often by incremental improvements, by trial and testing, by testing and adjustment; that is to say, by the mutual interplay of scientific knowledge and experienced performance rather than by direct prediction from fundamental principles. As Harvey Brooks has clearly pointed out: "Technological innovations usually arise out of a perception of a social need or market opportunity, not out of the conception of a potential application for a new scientific discovery.

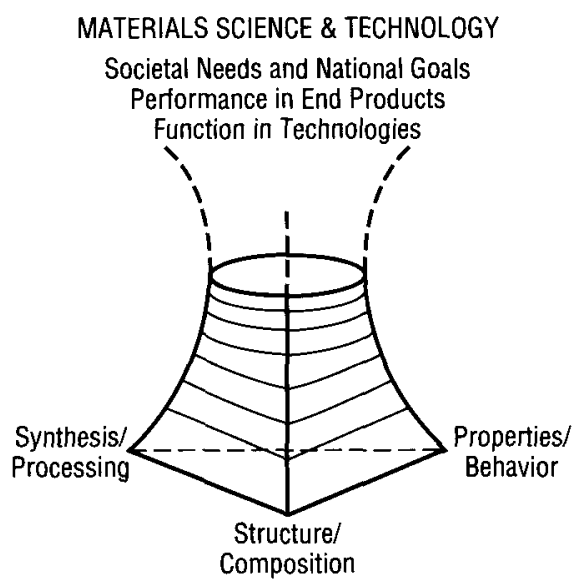

Figure 5. Portrayal of the merging of materials science and engineering with materials function in technologies and performance in end products.
Most of the research used in the innovation process is technologically driven and follows rather than precedes invention. Its product is useful technical knowledge which is sought not for its own sake, but in order to overcome a problem which becomes well-defined only after a new product or process is already in existence, at least in rudimentary form. One evidence for this is the fact that much of even the most fundamental research applicable to transistors and lasers, for example, took place after, not before, the basic invention Indeed, several studies in the innovation literature show that the highest appropriable returns are associated with incremental improvements on a radical invention rather than with the original invention itself." 9 This advice will undoubtedly be heeded in the Advanced Technology Program (ATP) administered by the National Institute of Standards and Technology, whose ATP budget was tripled in FY94 over FY93 and is projected to increase by an additional $125 \%$ (to $\$ 451$ million) in FY95 over FY94. It reflects the federal government's strategic shift from military to civilian technologies. The materials $R \& D$ community should respond to this national challenge.

Another growing societal issue, of major importance, is the environmental impact of industrial technologies and the balancing out of economic productivity versus environmental quality. ${ }^{10}$ Of course, there are many aspects of these nominally conflicting objectives, but in the process to minimize ecological damage and depreciation of natural resources, there will be increasing social pressure to avoid waste rather than to clean up after the fact. Such environmental concerns will make positive economic sense as the costs of environmental damage are internalized in the expense of manufacturing and in the environmental impact of the product. For example, there are indications that by 1996 the Department of Commerce intends to take the economic costs of air and water pollution into account in arriving at the national output. It has been estimated that U.S. industry now spends about $\$ 10$ billion annually just on environmental R\&D. So, in minimizing the environmental costs of evolving technologies, modern industry will be moving toward processing systems and products that must take the wastes into account, preferably throughout the design and manufacturing sequences. Clearly, industrial ecology is another major technological challenge that should motivate the materials R\&D community.

Indeed, Japan has already initiated a long-range $R \& D$ program through its 
Research Institute for Innovative Technology for Earth to work toward environmentally friendly technologies in the expectation that they will become commercially attractive in the long run. ${ }^{11}$ Such opportunities may also be unfolding in the United States; the Environmental Protection Agency's R\&D budget is now slated to increase by $13 \%$ to $\$ 383$ million in FY95. Here again, one can see the opportunity and support for new thinking on the part of the materials professionals toward a major national goal.

\section{Summing Up}

To sum up, it is evident that the multidiscipline of materials science and engineering is going through a vital change, not in its essential nature but in a redeployment of its efforts and in the ways that it can best serve society. This amounts to a rebalancing of outlook and emphasis rather than an actual paradigm shift. Synthesis of new materials with unusual structures and properties will still be as intellectually exciting as ever, but now national conditions are such that more focus on materials processing and performance is needed to enable further advances in useful and environmentally benign technologies that can lead to improved products on the world scene.

Actually, these challenges still remain within the original purview of MSE. To paraphrase from the 1974 COSMAT report on Materials and Man's Needs: Materials science and engineering intimately combines knowledge of the condensed state of matter with the real world of function and performance. It links the quest for deep and fundamental understanding of matter with the imperative of satisfying man's needs. Overall, materials science and engineering is a purposeful enterprise closely coupled to mankind's requirements for products, structures, machines, and devices. Herein lies its strength, value, and novelty. It promises deep contributions to the nation's prosperity, security, and quality of life. ${ }^{12}$

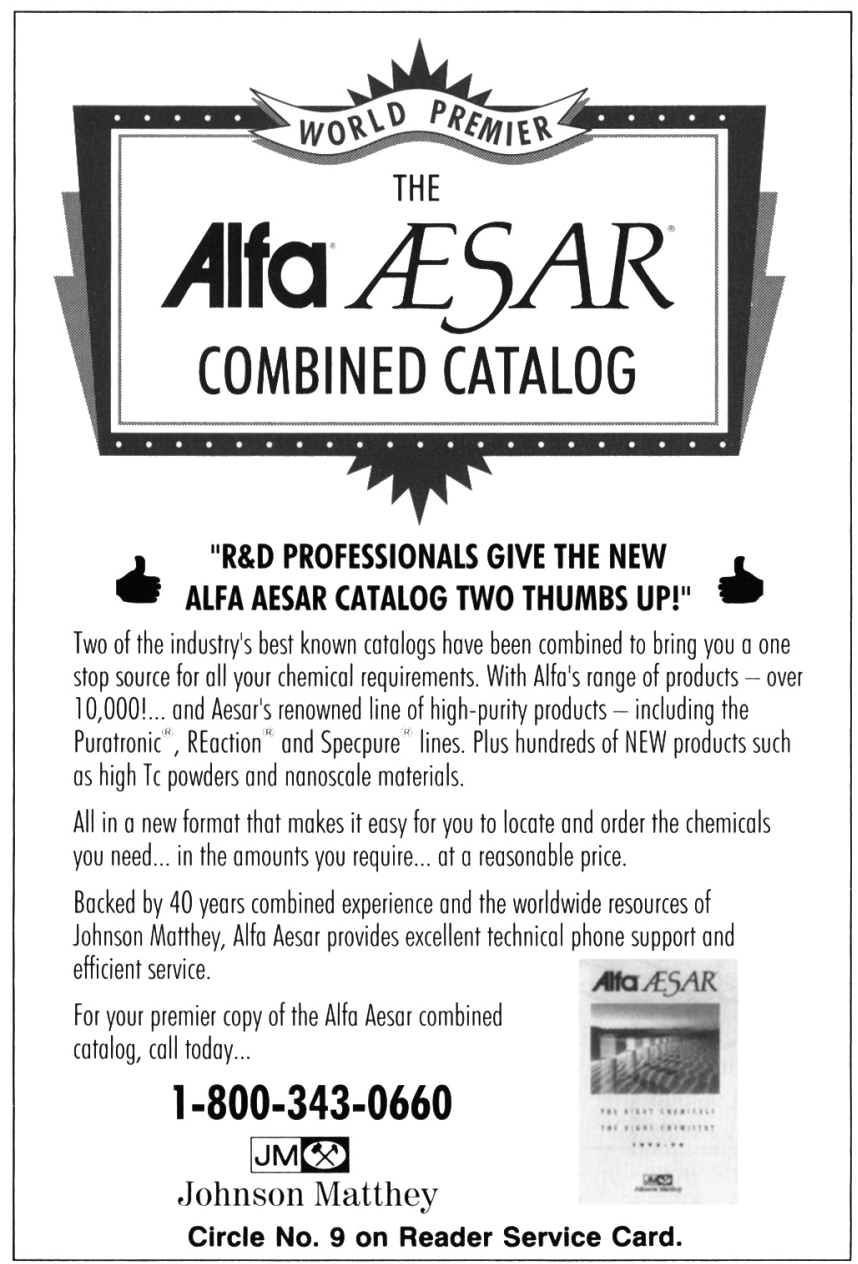

\section{Acknowledgments}

It is a pleasure to acknowledge the special help I have received in various ways from Drs. Jagdish Narayan of North Carolina State University, Rustum Roy of Pennsylvania State University, and Lyle $H$. Schwartz of the National Institute of Standards and Technology. I am also indebted to Miss Marguerite Meyer for her skill and patience during the many drafts caused by these rapidly changing times.

\section{References}

1. D. Turnbull, Annual Reviews of Materials Science (Palo Alto, CA, 1983) p. 1.

2. Materials and Man's Needs (National Academy of Sciences, Washington, DC, 1974).

3. Advanced Materials and Processing: The Fiscal Year 1993 Program, The Federal Program in Materials Science and Technology, Report of the Federal Coordinating Council of Sciences, Engineering, and Technology, (Washington, DC, 1992) p. 9. 4. Materials Science and Engineering for the 1990s, Report of the National Research Council (National Academic Press, Washington, DC, 1989) p. 29.

5. Technology for Economic Growth: President's Progress Report (The White House, Washington, DC, 1993).

6. Ibid., p. 22. Quotation of V. Bush, Science-The Endless Frontier, A Report to the President on a Program for Postwar Research (1945), reprinted by the National Science Foundation (1980).

7. Advanced Materials and Processing: The Fiscal Year 1994 Federal Program in Materials Science and Technology, Report of the FCCSET Committee on Industry and Technology (Washington, DC, 1993).

8. A. Gore, Reinventing GovernmentCreating a Government that Works Better and Costs Less, Report of the National Performance Review (U.S. Government Printing Office, Washington, DC, 1993) p. 51.

9. H. Brooks, in The Tochnology Race, Can the U.S. Win? The Herbert Hollomon Memorial Symposium, Center for Technology Policy and Industrial Development (MIT, 1991) p. 20.

10. S. Schmidheiny, Changing Course (MIT Press, Cambridge, MA, 1992).

11. Reference 9, p. 22.

12. Reference 2 , p. xxiii. 